\title{
Empirical Study on the Scale and Performance of China's Partial-Share Open-End Funds
}

\author{
Yinuo Ai \\ School of Shanxi University of Finance and Economics, Shanxi 030000, China. \\ m18834812046@163.com
}

\begin{abstract}
This article analyzes the impact of the scale of the Fund on the performance of the Fund in the second quarter of the 2009 year through 2015 year. The result is, the higher the Fund is, the performance of the Fund will be at an economically low level as the scale expands, then there is the stage of achieving economies of scale as the scale expands. Based on the analysis of fund performance through risk and excess profit, the paper puts forward relevant policy suggestions.
\end{abstract}

Keywords: Biased open-end Fund, Fund size, Fund performance, Empirical Analysis.

\section{Research Purposes}

The Fund is a financial investment tool that brings together a large number of small and medium investors to form a large amount of money and then entrusts it to a professional management company In theory, its scale advantage has: Reduce commission, reduce investment cost; Portfolio investment, reduce market risk; Expert finance, improve average income. China's Securities Investment Fund competition pattern has been preliminarily formed, the2015 Year Domestic fund company total number is expected to break through home, in the top 20 public offering fund companies occupy the entire market half of the foundation, all other public offering fund companies need for the remaining 50\% Market share "hand-to-hand", but also to guard against other market subjects to splitting this cake, competition is not very fierce. Under the background of increasingly homogeneous competition and the diversification of asset management means, the main index or reference factor of fund investors Choosing fund companies is the performance of fund companies. In other words, in the current context, fund companies need to constantly improve their own fund performance. And more and more fund companies adopt the approach of expanding the scale of and trying to achieve the scale effect in this way. Of course, the expansion of the Fund will also bring about the improvement of management costs, the difficulty of capital operation and so on. So how to balance the relationship between fund scale and fund performance, is an issue that deserves further study, based on this, the empirical study of fund size and fund performance in this paper, by using the data from the 2009 to 2015 China's biased open-end funds, I would like to analyze the correlation between the scale and performance of the Securities Investment Fund from the empirical analysis.

\section{Positive Analysis}

(I) selection of fund sizes

In order to explore the relationship between fund scale and fund performance, combined with stratified sampling criterion, the sample number per layer conforms to the actual ratio, this paper chooses the unit biased Stock Investment Fund (fund name and fund code see appendix). From the scale, the collected per biased funds are divided into three levels with 0-20 billion, 20-50 billion, and 50-130 billion, with sample numbers controlled at 8: All: 8 .

(II) Explore the selection of indicators

(i) Explore Indicator Identification

To explore the fund performance, can choose a lot of indicators, but from the perspective of investors, the Fund's actual profitability, risk management and excess performance indicators are the most concerned. From these three aspects, the yield, the standard deviation of the yield and the unit risk difference profit are the most ideal index.

(ii)Explore Indicator Time series Determination 
In the time series determination, this paper selects the average data of yield, yield standard deviation and unit risk difference profit in 2009-year -2014-year four quarter and the first two quarters of 2015 year. Try to find the internal rules of data from the annual data.

(iii) Explore the refinement of metrics

The average return rate can intuitively reflect the operation of the Fund, this paper chooses the quarter as the time unit, calculates the average yield of the fund, and the formula is as follows: $\frac{\sum \mathrm{Rt}}{\mathrm{M}}$

The principle of yield standard deviation is to choose the rate standard deviation by using risk model to measure the volatility of fund income the paper chooses the average calculation of quarterly yield standard deviation, the formula is: $\sqrt[2]{\frac{\sum(\mathrm{R}-\mathrm{E}(\mathrm{R}))^{2}}{\mathrm{M}}}$.

Unit risk Difference Profit Unit risk difference profit is within the evaluation period, the fund investment income exceeds the market management income that part and the fund return standard deviation ratio. In a sense, the larger the value, the better the performance of the Fund, the formula is: $\frac{E(R)-R_{m}}{\sigma}$

$\Sigma$ is the above-mentioned rate of return standard deviation, RM refers to the market without management average earnings, here is the Shanghai Composite Index closed average quarterly yield.

(iv) Research on the relationship between fund size and three indicators.

Relationship between fund size and quarterly average rate of return in order to further explore whether the two belong to the linear regression or the curve regression, this paper carries on the depth curve regression analysis to obtain the following results.

Table 1. Curve regression of fund scale and its quarterly average yield

\begin{tabular}{c|c|c|c|c|c|c}
\hline & R Square & F & Sig. & constant & b1 & b2 \\
\hline Linear & 0.182 & 5.548 & 0.027 & 0.011 & $6.955 \mathrm{E}-05$ & \\
\hline Secondary & 0.633 & 20.713 & 0.000 & 0.019 & 0.000 & $3.152 \mathrm{E}-06$ \\
\hline
\end{tabular}

As shown in table 1 , from the $\mathrm{R}$ side, the two-time equation of the fit is as high as 0.633 , indicating that the fitting effect is more ideal, and the inverse linear equation of the fit is not good, only 0.182 .

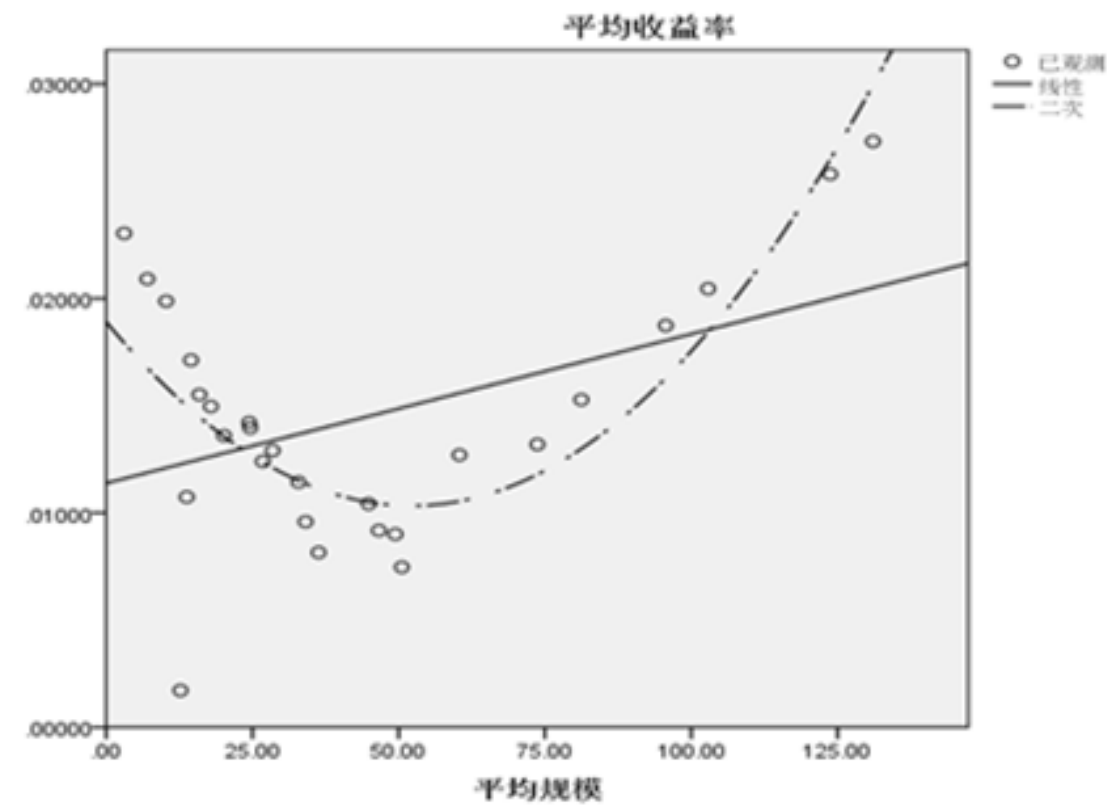

Figure 1 . The curve regression of fund size and its quarterly average yield

The synthesis diagram 1 and the table 1 know that the fund size and its quarterly average yield two curve regression, the regression equation from table 1 known as:

$\mathrm{Y}=0.000003125 \mathrm{X} 2+0.019$ 
From the regression chart and the regression equation, the average yield of the fund is not simply increased as the average size of the fund expands. In the early stage of the small scale, with the expansion of economic scale, the yield has declined, the scale of economic phenomenon. Only as the scale continues to increase, when the size of the fund reaches a certain level, the rate of return will be driven to increase.

On the scale of the Fund and its quarterly average yield two curve regression, it is not difficult to explain. After the initial expansion of the Fund, its corresponding management capacity and professional investment capacity has not improved, but it has become the burden and pressure of managers. So, the decline in profitability is not abnormal. As the fund continues to grow, attracting enough talent and good fund managers to join the fund, the average yield rises naturally.

(b) A study of the relationship between the size of the fund and the standard deviation of quarterly average returns

In order to further explore whether both of them belong to linear regression or curve regression, this paper makes a deep curve regression analysis of the two data and obtains the following results.

Table 2 . The curve regression between fund size and its quarterly average yield standard deviation

\begin{tabular}{c|c|c|c|c|c|c}
\hline & R Square & F & Sig. & constant & B1 & B2 \\
\hline Linear & 0.234 & 7.639 & 0.011 & 0.106 & 0.000 & \\
\hline Secondary & 0.692 & 26.970 & 0.000 & 0.094 & 0.000 & $-4.921 \mathrm{E}-06$ \\
\hline
\end{tabular}

As shown in table 2, from the $\mathrm{R}$ side, the two-time equation fits as high as 0.692 , indicating that the fitting effect is ideal, and the fit of the inverse equation is not good enough, only the 0.234.

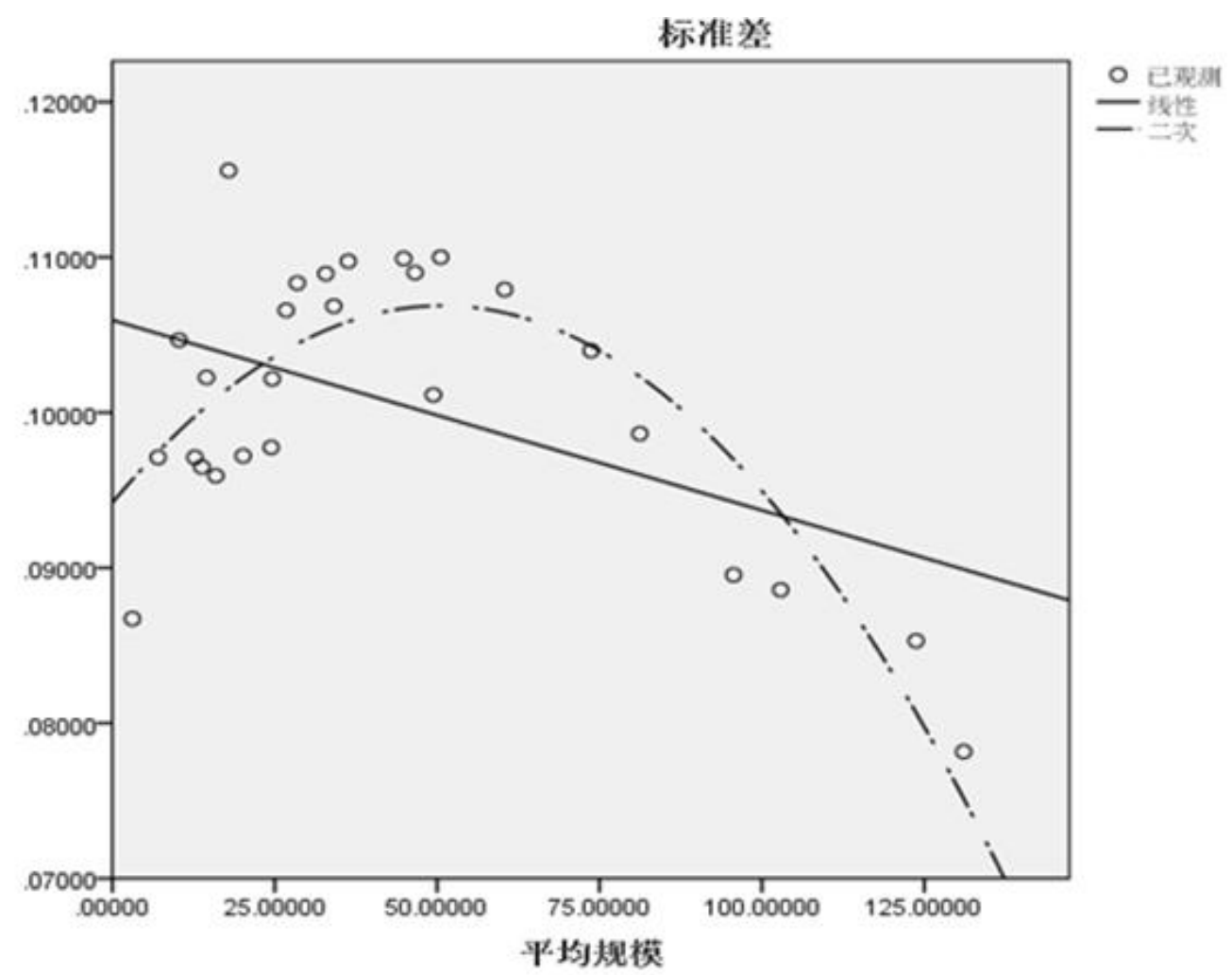

Figure 2. The curve regression between fund size and its quarterly average yield standard deviation

The synthesis diagram 2 and the table 2 know that the fund scale and its quarterly average yield standard deviation presents two times curve regression, its regression equation from table 2 known as:

$Y=-0.000004921 \times 2+0.094$ 
From regression chart and regression equation, the average yield standard deviation of the fund increases with the average size of the fund in a certain scale. With the expansion of economic scale to a certain stage, the rate of return standard deviation gradually declined.

The reason for the two returns of the standard deviation of fund scale and average return is that under the current capital market of our country, the small and medium sized funds have more flexibility in risk control, and they can also exert their advantages, when the fund scale is large, the ability of risk control decreases.

(c) The relationship between fund size and quarterly unit risk difference profit

In order to further explore whether both of them belong to linear regression or curve regression, this paper makes a deep curve regression analysis of the two data and obtains the following results.

Table 3. The curve regression of the fund size and its quarterly unit risk difference profit

\begin{tabular}{c|c|c|c|c|c|c}
\hline & R Square & F & Sig. & constant & B1 & B2 \\
\hline Linear & 0.298 & 10.624 & 0.003 & -0.048 & 0.001 & \\
\hline Secondary & 0.667 & 24.064 & 0.000 & 0.001 & -0.002 & $2.053 \mathrm{E}-05$ \\
\hline
\end{tabular}

As shown in table 3 , from the $\mathrm{R}$ side, the two-time equation fits as high as 0.667 , indicating that the fitting effect is ideal, and the fit of the inverse equation is not good enough, only the 0.298.

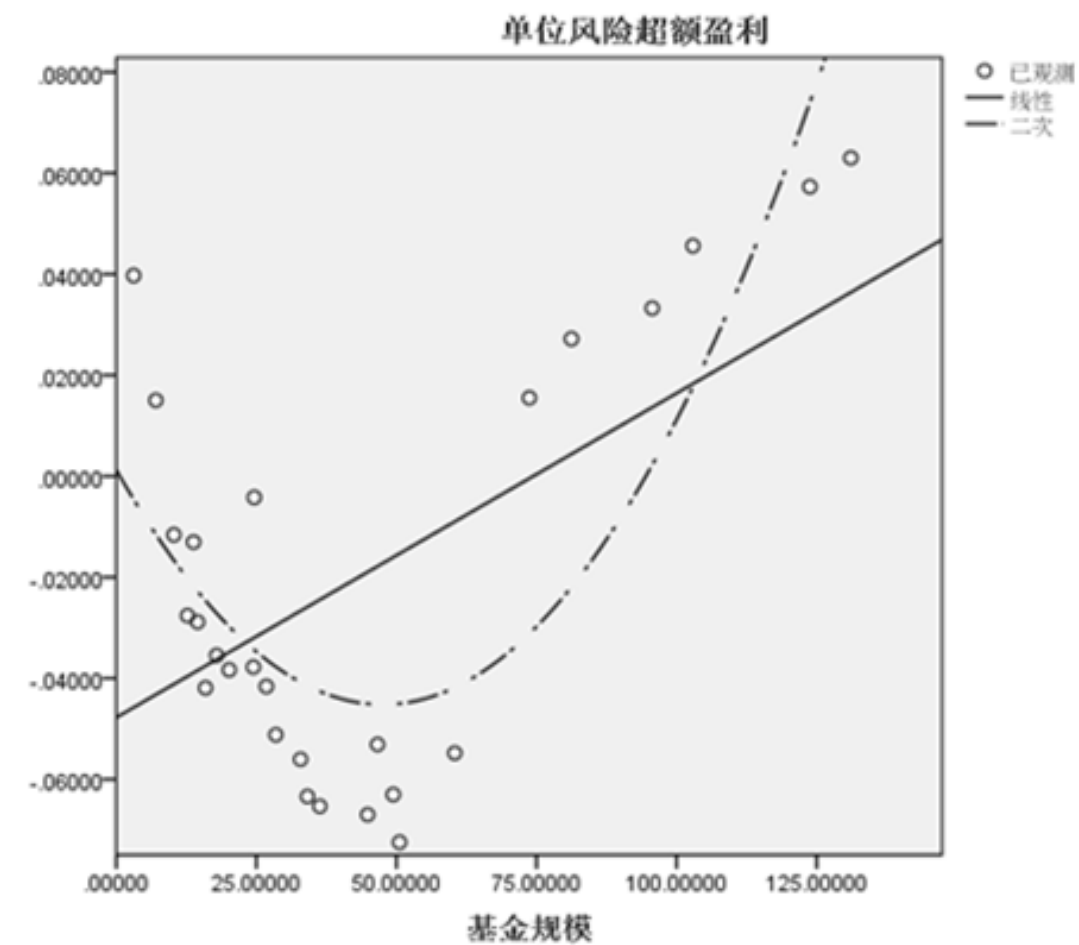

Figure 3. The return of the fund scale to its quarterly unit risk balance profit curve regression

The synthesis diagram 3 and the table 3 know that the fund size and its quarterly average yield two curve regression, the regression equation from table 3 known as:

$\mathrm{Y}=-0.00002053 \mathrm{x} 2-0.002 \mathrm{x}+0.001$

From regression charts and regression equations, the average yield of the fund does not rise or fall as the average size of the fund expands. In the early stage of the small scale, with the expansion of economic scale, the unit risk of excess profit decline, the scale is not economic phenomenon. Only with the continuous increase in scale, in the fund scale to a certain extent, the unit risk excess profit will be led to increase. From the empirical results, in the fund size is less than million, investors are difficult to obtain excess profit, and only when the fund size billion, the larger the scale, the greater the ability to gain excess profits. 


\section{Conclusions and Recommendations}

(a) Based on the above study, author concludes:

(1) In the small (0-20 billion) in the early days, with the expansion of the economy, the yield decline, the scale of economic phenomenon. From this interval, the average yield standard deviation of the fund rises with the increase of average fund scale in a certain scale, at the same time, with the enlargement of economic scale, the unit risk excess profit declines and the scale is not economic phenomenon.

(2) Within the medium size (20-50 billion) interval, with the expansion of economic scale, the yield continued to decline, the average rate of return on the standard deviation indicator, began to have a gradual downward trend, and with the expansion of economic scale, Excess profit per unit risk continues to decline.

(3) In the larger (50-130 billion) range, the yield increases as the scale continues to increase. In terms of average yield standard deviation index, the rate of return standard deviation decreases gradually after the scale of economy expands to a certain stage. When the fund scale of million, the larger the scale, the greater the ability to gain excess profits.

(4) Under the current capital market environment of our country, Fund scale and fund performance have a certain linear correlation. Firstly, in the current capital market of our country, the relationship between the fund scale and the performance is a stage of economy of scale with the enlargement of scale, and then there is a stage of realizing scale economy with the enlargement of scale. In line with this is the market reaction of investors. Second, in a certain period of time, China's various types of securities investment funds generally have a profitability below the market (small funds except), volatility is significantly higher than the market, and does not clearly reflect the advantages of its expert's present wealth. The reason is that China's Securities investment fund Operation Market is not perfect, increased the risk of China's fund investment; On the other hand, it also shows that the operation performance of our fund company is still very low, and the management ability should be improved.

(5) Small-scale fund companies are more likely to achieve higher performance compared to large companies; Medium sized fund companies may have economies of scale as the size of the fund increases; the continued increase in the size of the fund, until the emergence of large-scale or even large-scale funds, will again lead to increased efficiency of the Fund.

(b) To make our country's securities fund market better development, here, also give the following suggestions:

(1) Actively optimizes the scale structure of the entire fund market. First of all, the establishment of small fund and super large-scale fund should be given priority in the new fund. At the same time, with the maturity of China's securities market, investors tend to be rational, I think should consider the further development of open-end funds, so that the majority of investors through the purchase or Redemption Fund unit share of the way

To determine the optimal size of the fund is the most efficient way to configure.

(2) To control the size of the fund, to stick to the diversification of the fund company, effectively reduce the total single

Vibration effect. At the same time, control the speed of the release of the fund, the continued control of the Fund's marketing, in the Fund's administrator, innovative pay mechanism, to ensure that its management capacity and asset management scale can match.

(3) Continue to standardize the securities market system and improve the operating mechanism. It is very important to improve the market evaluation system of listed companies, improve the structure and quality of listed companies, and enhance the disclosure system of information, so that the fund can choose stocks more effectively. At present, the serious problem of false accounting in the market of shares greatly weakens the basis for the scientific decision of the fund manager,

It is difficult to give full play to professional advantages and improve the market risk of investment funds.

(4) The further strengthens the governance of the fund company and enhances the fund management ability. On the one hand, we should further strengthen and perfect the corporate 
governance structure, actively promote the Independent Director system, so that the fair principle of safeguarding the interests of small and medium-sized investors and improve the efficiency of fund management companies are effectively reflected. On the other hand, the fund companies must practice hard skills, product

The introduction or development of their own financial experts and strive to improve the management of large funds operating capacity.

(5) The carries out financial innovation and establishes urgently needed new investment instruments in the capital market to reduce market risk. For example, the forthcoming index trading, index futures and other financial derivative hedging instruments can effectively help large scale securities investment funds diversify the market system risk, play the role of stabilizing the securities market. For the healthy and orderly development of securities investment funds, the establishment and improvement of these financial derivative instruments is an indispensable means of promotion.

\section{References}

[1]. Hanging. Research on the relationship between the scale and performance of open-end funds [J]. Modern economic information, 2013, 32.

[2]. Shang, Lin Shu, Chen. Why the return on fund investment is negatively correlated with the size of the fund 111 new theoretical explanations [J]. Art. 2009, 23.

[3]. Mr Lam, Zhenghuiqing, WN, Cheney. An empirical analysis of the scale and performance of security investment funds [J]. Business Studies, 2002 one 114.

[4]. Goshilian. An empirical study on the relationship between the scale of open fund and corporate performance [J]. Economic Jingle, 2009 (2) 95-98. 